\title{
The Need to Shift Focus Away from the Scale and Towards Lifestyle in Obesity Management
}

\author{
Zachary S Zeigler* \\ College of Science, Engineering, and Technology, Grand Canyon University, Phoenix, USA
}

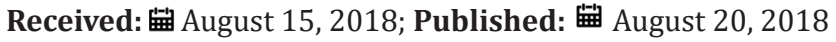

*Corresponding author: Zachary S Zeigler, College of Science, Engineering, and Technology, Grand Canyon University, Phoenix, USA

Keywords: Obesity Management; Scale; Lifestyle; Fat and Fit

\section{Opinion}

Obesity is a global problem, impacting an estimated 300 million people worldwide [1]. Its prevalence is increasing in both developed and developing countries throughout the world. In the United States, the prevalence of obesity is greater than it has ever been, with striking increases observed during the past 2 decades [2]. The economic costs of obesity are astounding. It is estimated that by the year 2030, 48-66 billion dollars/year will be spent on obesity related medical costs [3]. With the increased obesity prevalence and the accompanied disease risk associated with obesity [3], both healthcare provider and patient have a strong desire to lose weight. A 2003-2008 national survey of 16,720 Americans found that $73 \%$ of women and $55 \%$ of men have a desire to lose weight while approximately $50 \%$ of women and $30 \%$ of men actively engaged in weight loss efforts within the preceding year [4]. Disappointing, results from weight loss attempts are dismal at best. It was noted obesity researcher Albert Stunkard who stated, "most persons will not stay in treatment for obesity. Of those who stay in treatment, most will not lose weight, and of those who do lose weight, most will regain it". Stunkard's opinion has been verified through published studies that show successful treatment of obesity remains the exception rather than the rule. One of the more positive studies show that a mere $20 \%$ of obese persons who attempt to lose weight achieve and maintain clinically meaningful weight loss [5]. Attrition rates in obesity trials range from $10-80 \%$ [6]. In strictly controlled single-center randomized studies the attrition rate exceeds $40 \%$ at 12 months regardless of the type of dietary program [7].

\section{Achieving Clinically Meaningful Weight Loss}

Clinically, a $10 \%$ weight loss goal is recommended because a significant decrease in obesity-related mortality is seen [8]. Yet the majority of overweight/obese persons seeking weight loss consider $10 \%$ unsatisfactory [9]. It has been reported that women participating in weight-loss programs have an unrealistic goal weight as $32 \%$ lower than current body [9]. An analysis published in 2007[10] assessed weight outcomes in research studies with a minimum follow-up of 12 months to determine treatment effectiveness for weight loss and maintenance. Roughly 26,000 subjects spanning 80 studies were followed, and of that $26,000,31 \%$ decided to quit their respective study. Of those who did complete the study it was found that regardless of method of weight loss, average weight loss by 48 months was a mere $3 \%$ to $4 \%$ of starting body weight.

When unrealistic goals are set and unmet, something happens to the psyche that renders a feeling of defeat. Research on goal setting observes that when goals are not reached or when progress toward them are unsatisfactory, people have negative emotions [11], impaired task performance [12], and abandon their attempt to achieve their goal [13]. Unrealistic weight loss goals seem to support this as data show that a higher initial weight loss expectation predicts drop-out from the perspective weight loss program [14,15]. Additionally, small retrospective studies have found that having unrealistic weight loss goals may contribute to poor weight maintenance [16-18]. It has also been found that the time to drop-out is progressively shorter in relation to expected BMI loss [19]. It should be noted that the fitness and health community have been trying for the past three decades to reduce obesity rates with no success whatsoever. Do I need to remind all the definition of insanity, doing the same thing over and over again but expecting different results? It is my opinion that focus within the obese population needs to be shifted away from the scale to something more realistically achieved.

\section{Benefits of Lifestyle Change Independent of Weight Loss}

Missed in the "you must lose weight, or you will die" conversation is the plethora of data showing the ability to improve health in the absence of weight loss [20]. The DASH diet for example showed significant reductions in blood pressure $(-12 / 5 \mathrm{mmHg})$ in response to a diet intervention while weight was maintained [21]. 
Furthermore, both aerobic and resistance exercise have been shown to reduce hepatic and visceral fat without weight loss $[22,23]$. Additionally, lifestyle intervention, independent of weight loss, has shown to favorably impact diabetes risk [24], improved blood lipid profile [25], enhanced endothelial function [26], decreased inflammation [27], improved mitochondrial function [28], and improved postprandial metabolism [29]. Using the words of Blair and Le Monte [30] 'there has been an overemphasis on weight loss as a clinical target'. Because achieving a meaningful weight loss is elusive, emphasis should be shifted to health promoting lifestyle factors such as increasing fitness.

\section{Fat and Fit}

The concept of "fat and fit" has been most notably highlighted by Dr. Steve Blair as he has highlighted the importance of measured cardiovascular fitness on all-cause mortality [31,32]. Much of his data has been derived from the prospective Aerobic Center Longitudinal Study that followed $>80,000$ people over 35 years. A 2007 [33] paper by Dr. Blair examined the relationship among fitness level, different measures of fatness, and cancer mortality among men. It was found that regardless of BMI category, body fat percentage, or even waist circumference, it was better to be 'fat and fit' than to be normal weight but unfit. A 2010 review paper [34] assessed 36 studies that addressed the question, "which is a greater health risk, poor cardio-respiratory fitness or obesity". The outcomes that were looked at were mortality and morbidity, cardiovascular disease, and type 2 diabetes. It was found that the risk for all-cause and cardiovascular mortality was lower in individuals with high BMI and good aerobic fitness, compared with those with normal BMI and poor fitness. Other reviews have been conducted and agree that aerobic fitness counteracts the deleterious effects of obesity [35-37].

Observational prospective studies show that one can indeed be "fat and fit" [38]. A physically active lifestyle is associated with reduced CVD risk irrespective of abdominal adiposity. The EPICNorfolk study involving more than 10,000 subjects followed for over 10 years found that abdominally obese men and women who reported being active had lower CHD risk compared to inactive persons despite their abdominal obesity [39]. Work by Church and Blair found that among 2300 subjects with diabetes followed for roughly 16 years, poor fitness, not obesity, was associated with reduced survival probability [40]. Moving from sedentary to active activates genes that are involved in many structural, physiological, and metabolic adaptations that make the body more competent to perform physical activity but also provide cardiometabolic protection irrespective of weight loss [41].

\section{Conclusion}

To summarize, when an obese patient is assessed in the clinical setting, almost always advice to lose weight is given. Statistically speaking, the healthcare provider just asked the patient to do something very few can accomplish. On the other hand, even if some weight loss is seen, it is more than likely not enough to be deemed satisfactory to the patient. Thus, feelings of failure set in and eventually total recidivism is seen. In light of this, and when considering that genetics explains anywhere from $25-70 \%$ of body mass [42], maybe we shift the focus away from the scale and onto the behaviors that have been shown to produce positive health outcomes. Other researchers have suggested that focus be shifted to patients favorably changing lifestyle factors without placing a focus on weight loss [43]. Why not simply measure number of minutes engaged in physical activity, or measure fitness levels? These would be easily obtained outcome goals yet are almost never utilized in the clinical setting. The American College of Sports Medicine and the American Medical Association has initiated a global campaign titled Exercise is Medicine [44]. At the center of this campaign if for healthcare practitioners to actually "prescribe" exercise to their patients. It is my opinion that if the focus of obesity interventions where placed on physical activity adherence, not the scale, enhanced adherence rates would be witnessed, and consequentially improved health outcomes would be conferred.

\section{References}

1. World Health Organization (2018) Controlling the global obesity epidemic.

2. Flegal KM, Carroll MD, Kuczmarski RJ, Johnson CL (1998) Overweight and obesity in the United States: Prevalence and trends, 1960-1994. Int J Obes 22(1): 39-47.

3. Wang YC, McPherson K, Marsh T, Gortmaker SL, Brown M (2011) Health and economic burden of the projected obesity trends in the USA and the UK. The Lancet 378(9793): 815-825.

4. Yaemsiri S, Slining MM, Agarwal SK (2011) Perceived weight status, overweight diagnosis, and weight control among US adults: The NHANES 2003-2008 Study. Int J Obes 35(8): 1063-1070.

5. Allison P, David B, Pi-Sunyer, F Xavier (1995) Obesity treatment: Examining the premises. Endocrine Practice 1(5): 353-364.

6. Richman R, Burns C, Steinbeck K, Caterson I (1992) Factors influencing completion and attrition in a weight control programme. Obesity in Europe 91: 167-171.

7. Dansinger ML, Gleason JA, Griffith JL, Selker HP, Schaefer EJ (2005) Comparison of the Atkins, Ornish, Weight Watchers, and Zone diets for weight loss and heart disease risk reduction: A randomized trial. JAMA 293(1): 43-53.

8. Pi-Sunyer X (1998) Clinical guidelines on the identification, evaluation and treatment of overweight and obesity in adults-the evidence report. Obes Res 6: 51S-210S.

9. Foster GD, Wadden TA, Vogt RA, Brewer G (1997) What is a reasonable weight loss? Patients' expectations and evaluations of obesity treatment outcomes. J Consult Clin Psychol 65(1): 79-85.

10. Franz MJ, VanWormer JJ, Crain AL (2007) Weight-loss outcomes: A systematic review and meta-analysis of weight-loss clinical trials with a minimum 1-year follow-up. J Am Diet Assoc 107(10): 1755-1767.

11. Carver CS, Scheier MF (1990) Origins and functions of positive and negative affect: A control-process view. Psychol Rev 97(1): 19-35.

12. Cervone D, Jiwani N, Wood R (1991) Goal setting and the differential influence of self-regulatory processes on complex decision-making performance. J Pers Soc Psychol 61(2): 257-266.

13. Klinger E (1975) Consequences of commitment to and disengagement from incentives. Psychol Rev 82(1): 1-25.

14. Teixeira PJ, Going SB, Houtkooper LB (2002) Weight loss readiness in middle-aged women: Psychosocial predictors of success for behavioral weight reduction. J Behav Med 25(6): 499-523.

15. Teixeira P, Going S, Houtkooper L (2004) Pretreatment predictors of attrition and successful weight management in women. Int J Obes 28(9): 1124. 
16. Colvin RH, Olson SB (1983) A descriptive analysis of men and women who have lost significant weight and are highly successful at maintaining the loss. Addict Behav 8(3): 287-295.

17. Klem ML, Wing RR, McGuire MT, Seagle HM, Hill JO (1997) A descriptive study of individuals successful at long-term maintenance of substantial weight loss. Am J Clin Nutr 66(2) :239-246.

18. Marston AR, Criss J (1984) Maintenance of successful weight loss: incidence and prediction. Int J Obes 8(5): 435-439.

19. Dalle Grave R, Calugi S, Molinari E (2005) Weight loss expectations in obese patients and treatment attrition: An observational multicenter study. Obes Res 13(11): 1961-1969.

20. Gaesser GA, Angadi SS, Sawyer BJ (2011) Exercise and diet, independent of weight loss, improve cardiometabolic risk profile in overweight and obese individuals. The Physician and sports medicine 39(2): 87-97.

21. Sacks FM, Moore TJ, Appel LJ (1999) A dietary approach to prevent hypertension: A review of the Dietary Approaches to Stop Hypertension (DASH) Study. Clin Cardiol 22(S3): 6-10.

22. Hallsworth K, Fattakhova G, Hollingsworth KG (2011) Resistance exercise reduces liver fat and its mediators in non-alcoholic fatty liver disease independent of weight loss. Gut 60(9): 1278-1283.

23. Johnson NA, Sachinwalla T, Walton DW (2009) Aerobic exercise training reduces hepatic and visceral lipids in obese individuals without weight loss. Hepatology 50(4): 1105-1112.

24. Salas-Salvado J, Bullo M, Babio N (2011) Reduction in the incidence of type 2 diabetes with the Mediterranean diet: Results of the PREDIMEDReus nutrition intervention randomized trial. Diabetes Care 34(1): 14-9.

25. Snowling NJ, Hopkins WG (2006) Effects of different modes of exercise training on glucose control and risk factors for complications in type 2 diabetic patients: A meta-analysis. Diabetes Care 29(11): 2518-2527.

26. De Filippis E, Cusi K, Ocampo G (2006) Exercise-induced improvement in vasodilatory function accompanies increased insulin sensitivity in obesity and type 2 diabetes mellitus. The Journal of Clinical Endocrinology \& Metabolism 91(12): 4903-4910.

27. Kadoglou NP, Iliadis F, Angelopoulou N (2007) The anti-inflammatory effects of exercise training in patients with type 2 diabetes mellitus. European Journal of Cardiovascular Prevention \& Rehabilitation 14(6): 837-843.

28. Phielix E, Meex R, Moonen-Kornips E, Hesselink M, Schrauwen $P$ (2010) Exercise training increases mitochondrial content and ex vivo mitochondrial function similarly in patients with type 2 diabetes and in control individuals. Diabetologia 53(8): 1714-1721.

29. Weintraub MS, Rosen Y, Otto R, Eisenberg S, Breslow JL (1989) Physical exercise conditioning in the absence of weight loss reduces fasting and postprandial triglyceride-rich lipoprotein levels. Circulation 79(5): 1007-1014

ISSN: 2574-1241

DOI: $10.26717 / B J S T R .2018 .08 .001612$

Zachary S Zeigler. Biomed J Sci \& Tech Res

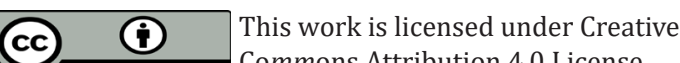

Submission Link: https://biomedres.us/submit-manuscript.php
30. Blair SN, LaMonte MJ (2005) Commentary: Current perspectives on obesity and health: Black and white, or shades of grey? Int J Epidemiol 35(1): 69-72.

31. Blair SN, Kampert JB, Kohl HW (1996) Influences of cardiorespiratory fitness and other precursors on cardiovascular disease and all-cause mortality in men and women. JAMA 276(3): 205-210.

32. Blair SN, Kohl HW, Barlow CE, Paffenbarger RS, Gibbons LW, et al. (1995) Changes in physical fitness and all-cause mortality: A prospective study of healthy and unhealthy men. JAMA 273(14): 1093-1098.

33. Farrell SW, Cortese GM, LaMonte MJ, Blair SN (2007) Cardiorespiratory fitness, different measures of adiposity, and cancer mortality in men. Obesity 15(12): 3140-3149.

34. Fogelholm M (2010) Physical activity, fitness and fatness: relations to mortality, morbidity and disease risk factors. A systematic review. Obesity reviews 11(3): 202-221.

35. Barry VW, Baruth M, Beets MW, Durstine JL, Liu J, (2014) Fitness vs. fatness on all-cause mortality: A meta-analysis. Prog Cardiovasc Dis 56(4): 382-390.

36. Gill JM, Malkova D (2006) Physical activity, fitness and cardiovascular disease risk in adults: interactions with insulin resistance and obesity. Clin Sci (Lond) 110(4): 409-425.

37. Pedersen B (2007) Body mass index-independent effect of fitness and physical activity for all-cause mortality. Scand J Med Sci Sports 17(3): 196-204.

38. Swift DL, Lavie CJ, Johannsen NM (2013) Physical activity, cardiorespiratory fitness, and exercise training in primary and secondary coronary prevention. Circulation Journal 77(2): 281-292.

39. Broekhuizen LN, Boekholdt SM, Arsenault BJ (2011) Physical activity, metabolic syndrome, and coronary risk: The EPIC-Norfolk prospective population study. European Journal of Cardiovascular Prevention \& Rehabilitation 18(2): 209-217.

40. Church TS, LaMonte MJ, Barlow CE, Blair SN (2005) Cardiorespiratory fitness and body mass index as predictors of cardiovascular disease mortality among men with diabetes. Arch Intern Med 165(18): 21142120.

41. Fiuza-Luces C, Garatachea N, Berger NA, Lucia A (2013) Exercise is the real polypill. Physiology 28(5): 330-358.

42. Stunkard AJ, Harris JR, Pedersen NL, McClearn GE (1990) The bodymass index of twins who have been reared apart. N Engl J Med 322(21): 1483-1487.

43. Garner DM, Wooley SC (1991) Confronting the failure of behavioral and dietary treatments for obesity. Clin Psychol Rev 11(6): 729-780.

44. Sallis RE (2009) Exercise is medicine and physicians need to prescribe it! Br J Sports Med 43(1): 3-4.

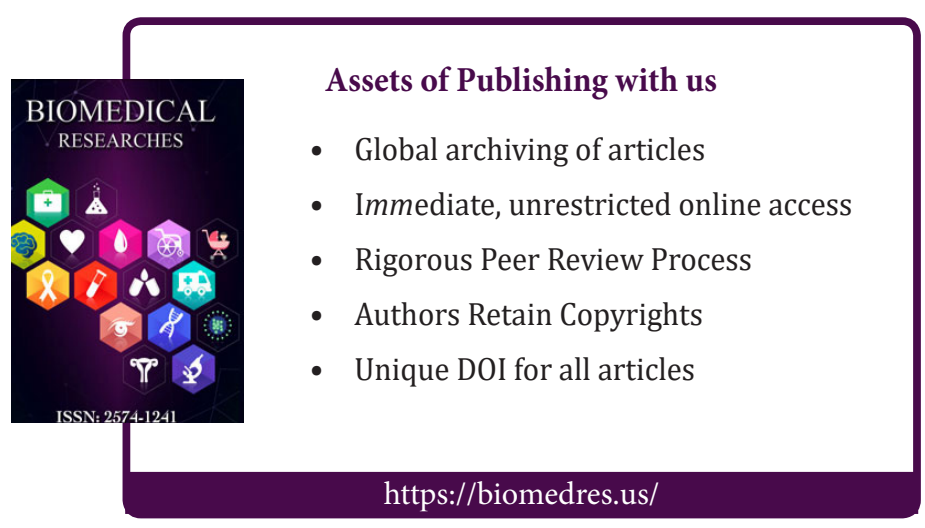

Cite this article: Zachary S Zeigler. The Need to Shift Focus Away from the Scale and Towards Lifestyle in Obesity Management. Biomed Sci\&Tech Res 8(2)- 2018. BJSTR MS.ID.001612. DOI: 10.26717/ BJSTR.2018.08.001612. 